DOI: 10.1515/ausp-2016-0023

\title{
Discourse Intonation and Information Structure: An Empirical Study of Existential There Constructions in Non-Native Spontaneous Speech
}

\author{
Judit NAGY \\ University of Szeged (Hungary) \\ Department of English Language Teacher Education and Applied Linguistics \\ nagyj@lit.u-szeged.hu
}

\begin{abstract}
The management of given and new information is one of the key components of accomplishing coherence in oral discourse, which is claimed to be a problematic area for language learners (Celce-Murcia, Dörnyei, and Thurrell 1995: 14). Research on discourse intonation proposes that instead of the given/new dichotomy, givenness should be viewed as a continuum, with different types of accessibility (Baumann \& Grice 2006). Moreover, Prince (1992) previously categorized information structure into Hearer-old/Hearernew and Discourse-old/Discourse-new information. There is consensus on the fact that focus or prominence associated with new information is marked with nuclear pitch accent, and its main acoustic cue, fundamental frequency (fo) (Ward \& Birner 2001: 120). Non-native intonation has been reported to display numerous differences in f0 range and patterns compared to native speech (Wennerstrom 1994; Baker 2010). This study is an attempt to address the issue of marking information structure in existential there sentences by means of fo in non-native spontaneous speech. Data originates from task-based interactions in the Wildcat Corpus of Native- and ForeignAccented English (Van Engen et al. 2010). This paper examines two issues: (1) information structure in relation to the notions of givenness and different types of accessibility (Baumann \& Grice 2006) and to Prince's (1992) multidimensional taxonomy and (2) the use of fo peaks to mark the prominence of new information. Several differences were measured among native speakers regarding the use of fo, sentence type, and complexity.
\end{abstract}

Keywords: non-native Englishes, discourse intonation, information structure, prominence, pitch accent 


\section{Introduction}

Discourse intonation has received an increasing amount of attention in recent years and it has become a central component of communicative competence stemming from its elemental role in top-down linguistic processing (Celce-Murcia 2007: 46). Among many other functions, it contributes to the structuring of discourse by signalling discourse segment boundaries, turn-taking, topic management, and marking information structure by highlighting new information (Celce-Murcia, Dörnyei, and Thurrell, 1995: 14). However, some researchers claim that intonation is difficult or even impossible to teach (Jenkins 2000), while others have provided empirical evidence for the effectiveness of visualization techniques in intonation teaching and raising phonological and metalinguistic awareness (Hardison 2004; Gorjian, Hayati, and Pourkhoni 2013; Levis \& Pickering 2004; Tanner \& Landon 2009; Chun 1998; Kaltenboeck 2001; Nagy 2014).

The effective development of communicative competence has become a highly debated and complex issue due to the use of English in international contexts by speakers of diverse backgrounds (Celce-Murcia 2007). The effect of the listener's native language is a basic factor to be addressed in non-native listening. Based on Major's (2001) model, Lecumberri et al. (2010) maintain that the effect of L1 is "inversely proportional to the level of phonological competence"; in other words, the L1 sound system has a greater influence in the initial stages of language acquisition, whereas in later stages universal and target-language features become more prominent (Lecumberri, Cooke, and Cutler 2010: 881). Furthermore, recent research suggests that L1 phonetic categories, or the so-called L1-category filter, in themselves do not provide explanation for non-native speech perception and processing. For example, non-native listeners were measured to outperform native English speakers in sound discriminations involving a sound which was not part of their native inventory. In addition to the effect of L1 categories, more general phonological principles and acoustic-phonetic factors, such as phonological features, appear to contribute to non-native speech perception and processing (Pajak \& Levy 2014: 148-149).

\section{Literature review}

\section{Non-native suprasegmentals}

There is a rapidly growing literature on the suprasegmental features of nonnative English yielding an abundance of empirical evidence for the role of suprasegmental features and the characteristics of non-native English (Chun 2002; Trouvain \& Gut 2007; Munro \& Derwing 1999; Baker 2010; Kang, Rubin, 
and Pickering 2010; Nagy 2009). However, the majority of studies have focused on word- or sentence-level phenomena, such as word stress or intonational patterns or contours (Cutler et al. 2007; Lai 2008; Nagy 2009). Along similar lines, Cutler et al. (2007) compared English and Dutch native speaker perception of English and Dutch lexical stress minimal pairs, and found that non-native Dutch listeners were able to use suprasegmental information more effectively in their native language, which was partly attributed to the greater importance of suprasegmental information in lexical recognition in Dutch. In other words, Dutch speakers did not rely on suprasegmental information in English although segmental cues are considered more important in lexical access in English compared to Dutch. However, in another task they outperformed native English speakers by transferring their native-language suprasegmental processing skills (Cooper, Cutler, and Wales 2002: 222-223). Lai (2008) examined the stress patterns of Mandarin EFL learners and native speakers in noun-verb minimal pairs, and found that Mandarin speakers used each correlate that was examined: duration, intensity, maximum fo and mean fo to distinguish nouns and verbs. Native speakers used mean and maximum fo, intensity and duration to mark stress for nouns, but only duration for verbs. Mandarin speakers, on the other hand, used the four correlates consistently for both nouns and verbs. The analysis of second formants revealed that native speakers reduce unstressed vowels in nouns and verbs, while Mandarin speakers only reduced unstressed vowels when they were situated in the second syllable (Lai 2008: 45-46). Wennerstrom (1994) examined several features of non-native intonation. The data was elicited in an oral reading task and a structured free-speech task. The analysis focused on high phrase accents, high pitch accents, low pitch accents, and high boundary tones. The study concluded that among native speakers intonational units are similar to grammatical units in their significance and predictability (Wennerstrom 1994: 415). Moreover, non-native speakers were found to use intonational patterns differently compared to native speakers. In a study of non-native focus acquisition, Baker (2010) identified several differences in non-native speech such as higher fo maxima, larger fo ranges, and stronger pitch accent cues (Baker 2010: 212).

However, there has been relatively little research on non-native suprasegmental features above sentence level, or non-native spontaneous speech (Pickering 2004; Hirschberg et al. 2007; Trouvain \& Gut 2007; Chun 2002; Nagy 2015). This is partly due to the complexities of suprasegmental features. Firstly, the difficulties associated with the measurement of the perception of intonation originates from a variety of factors such as the presence of multiple cues and cue trading, and the fact that intonational cues may serve diverse functions in different languages. Additional issues arise from the fact that fo perception is also connected to higherlevel linguistic processing. In addition, the combination of discrete and continuous features of intonation makes the measurement of fo perception a challenging 
endeavour (Vaissière 2008: 239-241). Moreover, non-native suprasegmental features need to be examined thoroughly, with attention to phonetic and phonological factors. Some non-native errors have been misinterpreted due to a difference in the intonational patterns or the use of acoustic cues (Mennen 2004: 58-59).

Vaissière (2007) provides an overview of the issues associated with the study of intonation including the effect of phonetic context, discourse context, languagespecific and non-language-specific processes. Among others, fo features are not independent of the intrinsic fo, loudness, duration of the segment, the quality of surrounding sounds, the discourse intention of the speaker, pragmatic meanings, or the language-specific use and perception of suprasegmental features (Vaissière 2008: 242). However, non-language specific or universal aspects have also been proposed. Gussenhoven (2004) proposes the three biological codes, the Frequency Code, The Effort Code, and The Production Code, providing an explanation for the universal features underlying the interpretation of pitch variation. These include affective and informational interpretations, but in each case reflect universal form-function relations (Gussenhoven 2004: 79). Prominence is the informational interpretation of the Effort Code, grammaticalized as focus. The Effort Code refers to the increased articulatory effort associated with certain meanings, resulting in increased articulatory precision and greater pitch excursion. However, increased pitch does not necessarily create an effect of prominence. Prominence is perceived on the basis of deviation from a reference line, such as the speaker's pitch register (Gussenhoven 2004: 85). In other words, the Effort Code is related to the speaker's wish to convey meaning that is considered important. This meaning of importance is grammaticalized as focus. The most common type of focus is presentational focus or information focus, which is usually not distinguished from corrective focus in English, which uses pitch accents to mark focus constituents. Besides intonation, languages may use other linguistic devices to mark information structure, such as syntactic structure or focus particles (Gussenhoven 2004: 86-87).

\section{Information structure, focus, and sentence structure}

One of the central elements of discourse intonation is its function marking information structure. Focused elements and new information are marked with prosodic prominence, generally denoted with the term nuclear pitch accent (Ward \& Birner 2001: 120). According to Chafe (2001), information structure is managed in interactions by the management of focus and periphery. The former is marked with "distinctive terminal intonation contour, an initial resetting of the pitch baseline, the presence of silence before and after, a change of tempo at the beginning or end, and boundary changes in voice quality such as whispering or creaky voice" (Chafe 2001: 675). Furthermore, Hirschberg et al. (2007) provide 
empirical evidence for the use of downstepped contours for topic and information structure marking in read and spontaneous Standard American English (SAE). They conclude that downstepped pitch accents are associated with given or inferrable information. However, the issue that they also appear with new information remains unresolved (Hirschberg et al. 2007: 22).

The consensus view seems to be that information status should not be conceptualized as a dichotomy of new vs. given/old information. Prince (1992) defined information status along two dimensions, namely the Hearer and the Discourse. New information in this respect may be known to one or more participants of the interaction, and thus be Hearer-old, yet it can be Discoursenew in case it had not been previously mentioned during the interaction. In addition, some information may belong to the category of Inferrables, which means that it is accessible (Prince 1992: 309). Furthermore, some researchers proposed additional subcomponents of signalling information status, such as salience and focus of attention, and advocated that givenness should be viewed as a continuum which includes the two extremes of new and given status and the intermediary textual, situational, and inferential accessibility (Venditti \& Hirschberg 2003; Baumann \& Grice 2006).

The role of intonation in syntactic disambiguation has also been extensively examined among native speakers. Warren et al. (2000) examined durational differences in the disambiguation of syntactically ambiguous sentences elicited in a cooperative game task. The speakers and listeners were naïve native speakers. Their results show that prosody was used in the disambiguation process even when speakers had access to situational information aiding disambiguation. The authors argued that prosody fulfils an important role in sentence comprehension (Warren et al. 2000: 24). Schafer et al. (2000) examined the prosodic features of data collected with the same cooperative game task presented in Warren et al. (2000). Their results corroborate the previous results that prosodic disambiguation is likely to contribute to sentence comprehension in a variety of discourse situations. However, their results revealed that prosodic structure cannot be predicted solely based on syntactic structure (Schafer, Speer, Warren, and White 2000: 180). Van de Vijver et al. (2006) examined fo and duration of focused lexical items in an experimental setting in different focus conditions, namely prosodic focus marking (question-answer pairs), syntactic focus marking (clefts/declarative sentences), and lexical focus marking (only as a focus marker). The results showed that only nuclear accent had an effect on the duration and pitch of focused lexical items, and not syntactic or lexical focus marking (van de Vijver, Sennema, and Zimmer-Stahl 2006: 217-218).

As regards language learners, there is evidence pointing to the varying degree of effectiveness in L2 use of prosody for syntactic disambiguation and the dominance of contextual cues over prosodic ones (Ying, 1996: 698). Sennema et al. (2005) 
found that the position of the word in the sentence was the strongest cue in lexical recognition and recall among German L2 learners. Prosodic focus marking was found to play only a supporting role in the recognition of words in sentence initial or final position. However, prosodic focus marking has a stronger effect on words occurring in medial position (Sennema, Vijver, and Carroll 2005: 196-197).

Finally, presentation of new information may be linked to specific structures, such as existential there sentences, which are non-canonical structures with a postposed logical subject and the expletive there occupying the canonical subject position. As regards information structure, existential there sentences are used to express Hearernew information. Hearer-old NP-s result in infelicitous sentences and are not allowed in the postverbal position of existential there sentences (Ward \& Birner 2001: 127). In addition, information status is also connected with definiteness (expressed by the definite article, demonstrative articles, possessive adjectives, personal pronouns, and proper nouns), as Hearer-old information is usually definite, while Hearer-new information is usually indefinite (Prince 1992: 299-302).

\section{Research questions}

1. Do native speakers (NS) and non-native speakers (NNS) use different sentence types when they present Hearer-New information? Are existential there constructions used to present Hearer-new information?

2. Do NS or NNS use more complex sentences when they present Hearer-new information?

3. Do NS and NNS use fo to mark prominence of new information differently in various sentence types? Is the Hearer-new word marked with an fo maximum?

\section{Methodology}

This article analyses data from the Wildcat Corpus of Native- and ForeignAccented English. The corpus contains scripted and spontaneous recordings of native (NS) and non-native speakers (NNS) of varied linguistic backgrounds involving 76 speakers from 13 native language backgrounds, in both native and non-native pairings. Recordings were carried out in a sound-treated booth in the Northwestern University Phonetics Laboratory. The conversations were recorded in stereo using a Marantz PMD 670 flash recorder and participants wore AKG C420 headset microphones (Van Engen et al. 2010: 517).

I examined the spontaneous speech data from 10 out of the 37 currently available conversations recorded using the Diapix elicitation technique (see Appendix 1), which involved 10 native and 10 non-native speakers (14 males 
and 6 females) participating in a spot-the-difference task. The total duration of the 10 interviews selected for analysis was 3:10 hours. In order to complete the task, the two speakers had to cooperatively identify the differences in the two pictures they had been presented with. Each speaker underwent a familiarization task before the recording. For the purpose of reducing the effect of speech accommodation, conversations with NS-NS and NNS-NNS pairs were included. Prior to recording, participants were evaluated by native speakers of American English for accentedness on a scale of 1 (no foreign accent) to 9 (very strong foreign accent). A marked difference was found in the accent of native and nonnative speakers. The average NS accentedness rating was 1.27 , with ratings ranging from 1.04 to 1.67 , while the average NNS rating was 6.35 , with a range of 3.10 to 8.31 (Van Engen et al. 2010: 518-519).

Data analysis and measurements were carried out using Praat version 6.0.12. (Boersma \& Weenink 2016). The word boundaries established in the corpus transcription, produced by hand-corrected automatic alignment of orthographic transcription, were individually re-examined and additional hand corrections were made (Wildcat Corpus of Native- and Foreign-Accented English, n.d.). In the first stage of data analysis, I added a new tier (InfoStatus) and I labelled the first occurrences of keywords containing Hearer-new information. Changed items in the Diapix task were used as keywords. I also added a further tier (SentType), which was used for the hand-labelling of sentence types in which Hearer-new information appeared. Sentence labels included declarative, ellipsis, possessive, there, there_nf (new information keyword not in focus position), interrogative, and other. These tiers and labels were used to extract new information sentences from the LongSound files. File extraction was carried out using the Massive Speech Corpus Tool (MaSCoT) (Sadowsky 2016), and resulted in 78 sound files and corresponding Praat TextGrid files.

Measurements were carried out with a script based on Mietta Lennes's Speech Corpus Toolkit for Praat (Lennes 2011). Maximum, minimum, and mean fo, and standard deviation were measured in $\mathrm{Hz}$ on words containing Hearer-new information coupled with pitch accent (MaxFO, MinFO, MeanFo, FOSD) and the sentences containing these words (MaxFoSent, MinFoSent, MeanFoSent and FOSDSent). In addition, the number of words was also measured for each sentence based on the number of intervals in the mixed tier of the corpus containing the word-level transcription of the interactions. These measurements were used to calculate $n_{-}$words, thus categorizing sentences into 1-3-word, 4-6-word, 7-9-word, 10-12-word, and 13+ word sentences. Finally, the normalization of fundamental frequency measurements was carried out by calculating fo z-score values (FOZ-SCore). It must be noted that additional issues stem from the segmental effects influencing fo values, which at this stage of analysis are viewed as inherent features of naturally occurring speech (Pierrehumbert 1980: 14). 


\section{Results and discussion}

\section{Sentence types presenting hearer-new information}

The first question was aimed at the NS and NNS use of different sentence types when they present Hearer-new information. Contrary to preliminary assumptions, existential there only appeared in $5 \%$ of the NS sentences and $3 \%$ of NNS sentences. Additional examination of the larger sample provided evidence for the extensive use of existential there sentences in the Diapix interactions in sentences not containing the keywords selected for this analysis. The information structure and prosodic features of these existential there sentences are open for further research.

Declarative sentences were the most frequently occurring sentence type both among native (33\%) and non-native speakers (47\%). Native speakers also preferred possessives (30\%) and ellipsis (23\%), whereas non-natives used ellipsis $(26 \%)$ and interrogatives (11\%) more frequently. Possessives were less frequently used by non-native speakers (7.9). However, according to a Chi-square test, there was no significant relationship between nativeness and sentence type: $\chi^{2}(6)=$ 8.54, $p \geq .05$.

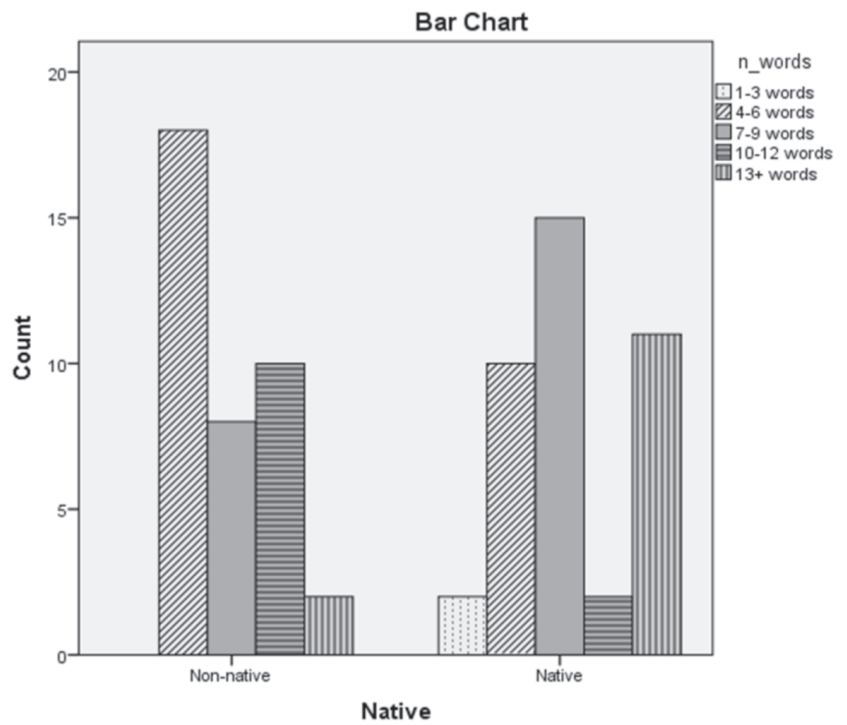

Figure 1. NS vs NNS distribution of sentence complexity 


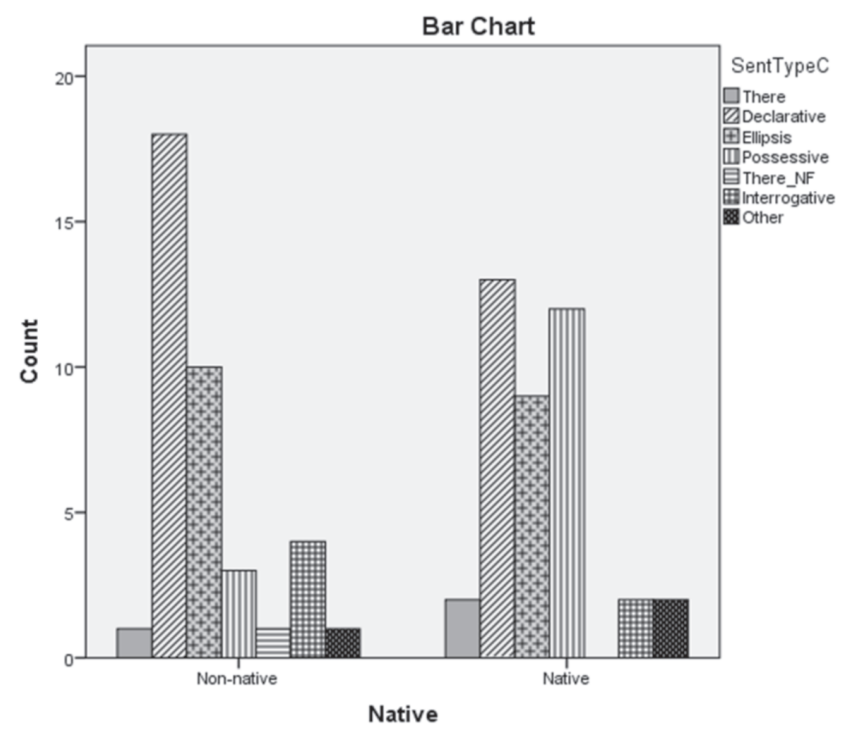

Figure 2. NS vs NNS distribution of sentence types

\section{Sentence complexity}

The relationship between nativeness and the complexity of sentences containing Hearer-new information was also examined. As an initial step in examining sentence complexity, I examined the number of words each sentence contained. This was accomplished by counting the number of intervals in the text grid tier containing word-level transcription, which also included spontaneous speech phenomena such as repetitions or filled pauses. Non-native speakers ( $\mathrm{N}=38$ ) mostly used shorter sentences: $47 \%$ of their sentences contained 4-6 words, whereas native speakers $(\mathrm{N}=40)$ preferred sentences containing 7-9 words. Sentences consisting of a higher number of constituents were more frequently used by native $(27 \%)$ than non-native speakers $(5 \%)$. An additional difference was in the use of 1-3-word sentences, which only occurred among native speakers. In general, non-native speakers tended to use shorter sentences focusing on one piece of new information, whereas native speakers were found to use longer sentences as a result of presenting information in more detail or demonstrating more frequent use of spontaneous speech phenomena. Figure 3 presents the distribution of sentence complexity among native and non-native speakers as measured by the number of intervals in TextGrid files corresponding to the number of words in each sentence.

According to the results of a Chi-square test, there was a significant relationship between nativeness and the complexity of sentences: $\chi^{2}(4)=17.94, p \leq .001$. The Cramer's V=.48 value measuring association demonstrates a strong relationship between the variables. 


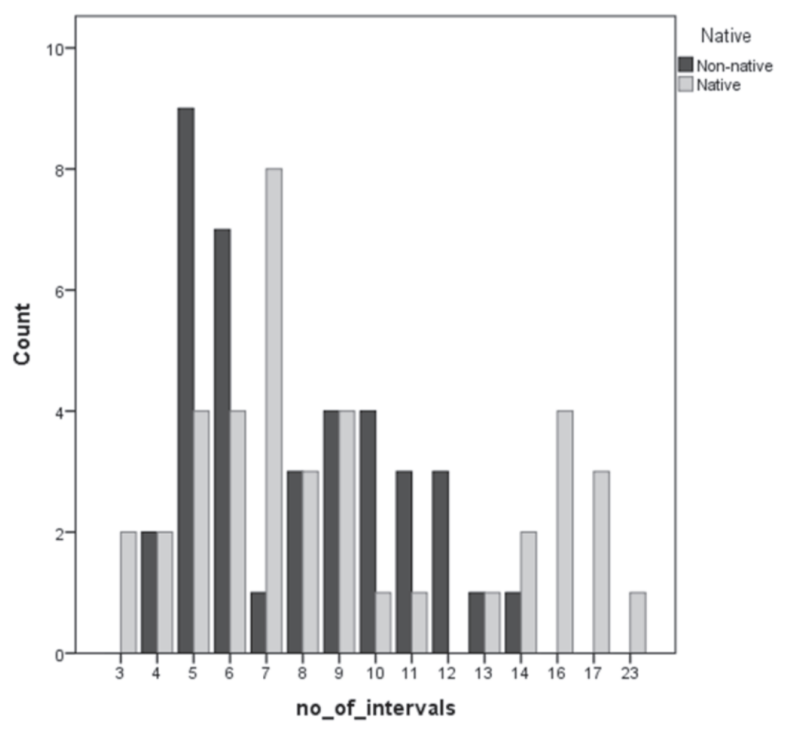

Figure 3. NS and NNS distribution of sentence complexity

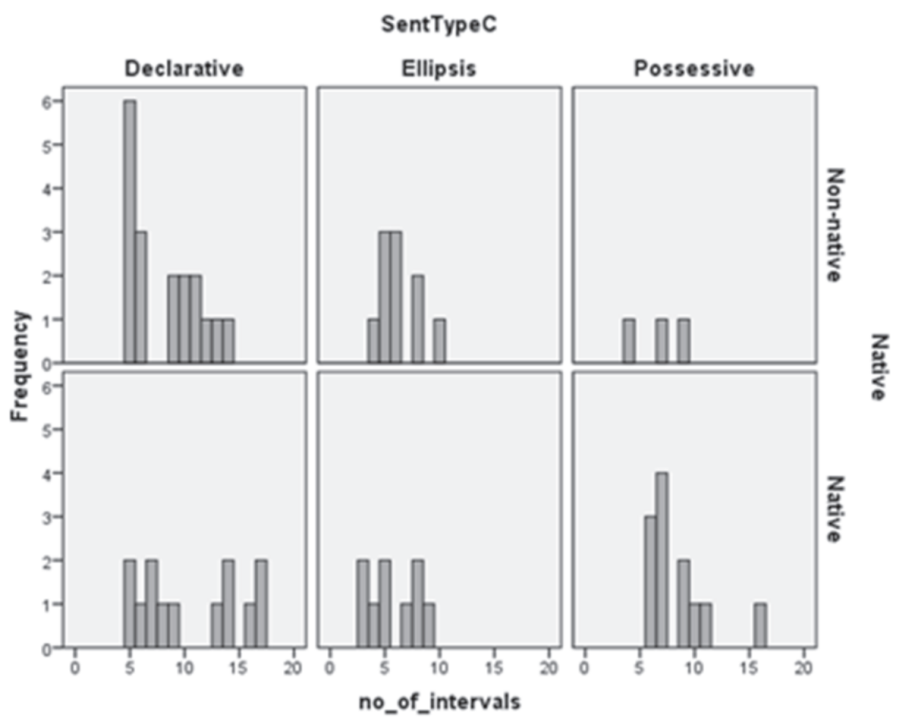

Figure 4. NS and NNS sentence complexity in the three main sentence types

Furthermore, several differences were found in the sentences of native and non-native speakers after examining the relationship between sentence types and complexity. Declaratives were more complex among native speakers, while non-native speakers used sentences of varying complexity. Ellipsis occurred in shorter sentences among native speakers compared to non-natives. However, 
the most marked difference was found in possessive sentences, where native speakers used longer sentences considerably more frequently (Figure 4). Sentence complexity can be further signalled by the presence of additional fo peaks, which is briefly discussed in the following section.

\section{Fo marking prominence in various sentence types}

The third research question focused on the role of fo in marking prominence of new information and its relation to various sentence types. The preliminary visual inspection revealed that the data was not normally distributed; as a result, nonparametric tests were used. In addition, scatterplots were used to verify the monotonic relationship. An independent-samples Kruskal-Wallis test revealed no significant differences among NS and NNS fo z-scores. Nonetheless, visual inspection of fo z-scores showed a different distribution among native and nonnative speakers in the most frequently used sentence types $\left(\mathrm{N}_{\mathrm{DECL}}=31, \mathrm{~N}_{\mathrm{ELL}}=19\right.$, $\mathrm{N}_{\text {poss }}=15$ ) (Figure 5). Consequently, further research on a larger sample is needed to map the differences between native and non-native speakers.

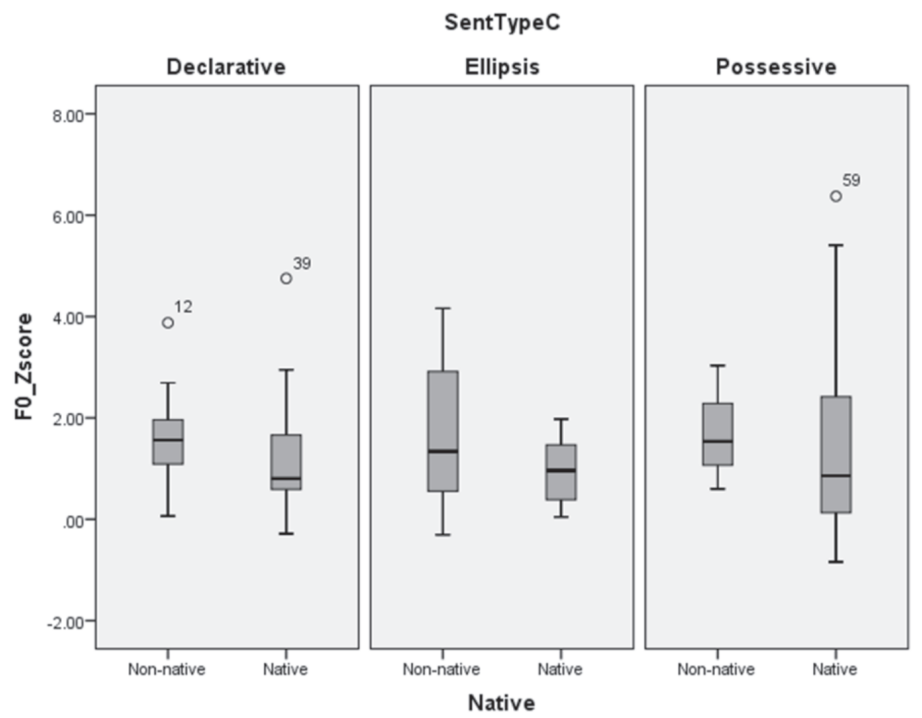

Figure 5. NS and NNS fo z-score values in the three main sentence types

An additional question concerning fo prominence was whether Hearer-new information is marked with the highest fo peak of the sentence. The results of a Spearman correlation revealed a strong positive correlation between MaxF0 and MaxFoSent $\left(\rho_{\mathrm{NS}}=.85, \mathrm{~N}_{\mathrm{NS}}=40, \mathrm{p}<.001\right)$ among native speakers, but only a moderate positive correlation among non-native speakers $\left(\rho_{\mathrm{NNS}}=.45, \mathrm{~N}_{\mathrm{NNS}}=40, \mathrm{p}<.001\right)$. A 
further distinction can be made by looking at gender differences. Unfortunately, at this stage, the sample size only allows for statistical testing among sentences

produced by male speakers $\left(\mathrm{N}_{\text {male }}=55, \mathrm{~N}_{\text {female }}=23\right)$. A Spearman correlation carried out among male non-native speakers uncovered a strong positive correlation between fo peaks measured on words carrying new information ( $\mathrm{MaxFO}$ ) and sentence-level fo peaks (MaxFoSent) $\left(\rho_{\mathrm{NNS}}=.85, \mathrm{n}_{\mathrm{NNS}}=31, \mathrm{p}<.01\right)$. Conversely, no similar significant relationship could be established among native speakers. Furthermore, a similar discrepancy between native and non-native speakers is observable when we examine the relationship between fo peaks in the three most commonly occurring sentence types ( $\rho_{\mathrm{NS}}=.87, \mathrm{~N}_{\mathrm{NS}}=31, \mathrm{p}<.01 ; \rho_{\mathrm{NNS}}=.45, \mathrm{~N}_{\mathrm{NNS}}=31$, $\mathrm{p}<.001$ ). In conclusion, the results indicate the need for an in-depth analysis of the relationship of fo and sentence types.

\section{Conclusions}

The data provides empirical evidence suggesting that native speakers used more complex sentences when they presented Hearer-new information. According to the initial hypothesis, native speakers were more likely to use longer sentences. In addition, the sentence-level fo maxima was less likely to overlap with fo maxima measured on Hearer-new words among native speakers. On the other hand, non-native speakers were more likely to emphasize Hearer-new words with fo peaks. Moreover, non-canonical structures were rarely used either by native or non-native speakers. Existential there sentences were found to occur in a small percentage. However, a preliminary examination of existential there sentences occurring independently of new information keywords revealed a considerable number of such structures in the Diapix interactions. A further research aim is to map the information structure of these additional existential there sentences.

Finally, native and non-native speech also diverged in the use of fo within sentences. Additional differences were found among the two groups in use of fo to mark the prominence of new information in different sentence types. However, the sample was not large enough to allow for generalizations at this point.

\section{References}

Baker, Rachel Elizabeth. 2010. The acquisition of English focus marking by nonnative speakers. (Doctoral dissertation). Northwestern University.

Baumann, Stefan-Martine Grice. 2006. The intonation of accessibility. Journal of Pragmatics 38(10): 1636-1657. 
Boersma, Paul-David Weenink. 2016. PRAAT: Doing phonetics by computer. http://www.praat.org

Celce-Murcia, Marianne. 2007. Rethinking the role of communicative competence in language teaching. In: E. Alcón Soler, M. P. Safont Jordà (eds), Intercultural language use and language learning, 41-57. Dordrecht: Springer.

Celce-Murcia, Marianne-Dörnyei, Zoltán-Thurrell, Sarah. 1995. Communicative competence: a pedagogically motivated model with content specifications. Issues in Applied Linguistics 6(2): 5-35.

Chafe, Wallace. 2001. The analysis of discourse flow. In: Schiffrin, Deborah, Deborah Tannen, Heidi E. Hamilton (eds), The handbook of discourse analysis, 673-687. Blackwell Publishing Ltd.

Chun, Dorothy M. 1998. Signal analysis software for teaching discourse intonation. Language Learning and Technology 2(1): 61-77.

2002. Discourse intonation in L2: from theory and research to practice. Discourse. Amsterdam/Philadelphia: John Benjamins Publishing.

Cooper, Nicole-Cutler, Anne-Wales, Roger. 2002. Constraints of lexical stress on lexical access in English: evidence from native and non-native listeners. Language and Speech 45: 207-28.

Cutler, Anne-Wales, Roger-Cooper, Nicole-Janssen, Joris H. 2007. Dutch listeners' use of suprasegmental cues to English stress. In: Trouvain, J., Barry, W. J. (eds), Proceedings of the $16^{\text {th }}$ International Congress of Phonetics Sciences, 19131916. Dudweiler: Pirrot.

Engen, Kristin J. Van-Baese-Berk, Melissa-E. Baker, Rachel-Choi, Arim-Kim, Midam-R. Bradlow, Ann. 2010. The Wildcat Corpus of native- and foreignaccented English: communicative efficiency across conversational dyads with varying language alignment profiles. Language and Speech 53(4): 510-540.

Gorjian, Bahman-Hayati, Abdolmajid-Pourkhoni, Parisa. 2013. Using Praat software in teaching prosodic features to EFL learners. Procedia - Social and Behavioral Sciences 84: 34-40.

Gussenhoven, Carlos. 2004. The Phonology of tone and intonation. Cambridge: Cambridge University Press.

Hardison, Debra M. 2004. Generalization of computer-assisted prosody training: quantitative and qualitative findings. Language Learning and Technology 8(1): 34-52.

Hirschberg, Julia-Gravano, Agustín-Nenkova, Ani-Sneed, Elisa-Ward, Gregory. 2007. Intonational overload: uses of the downstepped $\left(\mathrm{H}^{*}\right.$ ! $\left.\mathrm{H}^{*}-\mathrm{L} \%\right)$ contour in read and spontaneous speech. Laboratory Phonology 9: 455-482.

Jenkins, Jennifer. 2000. The phonology of English as an international language: new models, new norms, new goals. Oxford: Oxford University Press. 
Kaltenboeck, Gunther. 2001. A multimedia approach to suprasegmentals: using a CD-ROM for English intonation teaching. Proceedings of Phonetics Teaching $\mathcal{\sigma}$ Learning Conference.

Kang, Okim-Rubin, Don-Pickering, Lucy. 2010. Suprasegmental measures of accentedness and judgments of language learner proficiency in oral English. Modern Language Journal 94: 554-566.

Lai, Yuwen. 2008. Acoustic realization and perception of English lexical stress by Mandarin learners (Unpublished doctoral dissertation). University of Kansas.

Lecumberri, Maria Luisa Garcia-Cooke, Martin-Cutler, Anne. 2010. Non-native speech perception in adverse conditions: a review. Speech Communication 52(11-12): 864-886.

Lennes, Mietta. 2011. SpeCT - The Speech Corpus Toolkit for Praat. http://www.helsinki.fi/ lennes/praat-scripts/ (1 January, 2016).

Levis, John M.-Pickering, Lucy. 2004. Teaching intonation in discourse using speech visualization technology. System 32: 505-524.

Major, Roy C. 2001. Foreign accent: the ontogeny and philogeny of second language phonology. New Jersey: Lawrence Erlbaum Associates.

Mennen, Ineke. 2004. Bi-directional interference in the intonation of Dutch speakers of Greek. Journal of Phonetics 32: 543-563.

Munro, Murray J.-M. Derwing, Tracey. 1999. Foreign accent, comprehensibility, and intelligibility in the speech of second language learners. Language Learning 49(Supplement 1): 285-310.

Nagy, Judit 2009. Magyar nyelvtanulók angol lexikai hangsúlyának akusztikai vizsgálata [An acoustic phonetic study of Hungarian language learners' lexical stress]. In: Váradi, Tamás (ed.), Alkalmazott Nyelvészeti Doktorandusz Konferencia 3: 87-98. Budapest: MTA Nyelvtudományi Intézet.

2014. The use of speech visualization technology in prosody teaching. In: Varga, Cristina (ed.), New trends in language didactics: Noi direcții în didactica limbilor, 95-107. Cluj: Presa Universitară Clujeană.

2015. The use of intonational cues marking new information in non-native speech. EduLingua 2(1): 1-14.

(forthcoming). Features of native and non-native spontaneous speech presenting new information. Proceedings of the $6^{\text {th }}$ ELLE International Conference on English Language and Literatures in English. Oradea: Romania: Partium Christian University.

Pajak, Bozena-Levy, Roger. 2014. The role of abstraction in non-native speech perception. Journal of Phonetics 46: 147-160.

Pickering, Lucy. 2004. The structure and function of intonational paragraphs in native and non-native speaker instructional discourse. English for Specific Purposes 23(1): 19-43. 
Pierrehumbert, Janet Breckenridge. 1980. The phonology and phonetics of English intonation (Unpublished doctoral dissertation). Massachusetts Institute of Technology.

Prince, Ellen F. 1992. The ZPG letter: subjects, definiteness, and informationstatus. In: Mann, William C., Thompson, Sandra A. (eds), Discourse description: diverse analyses of a fund raising text, 295-325. Amsterdam/Philadelphia: John Benjamins.

Sadowsky, Scott. 2016. Massive Speech Corpus Tool (MaSCoT) 2.4. http:// sadowsky.cl/praat.html.

Schafer, Amy J.-R. Speer, Shari-Warren, Paul-White, S. David. 2000. Intonational disambiguation in sentence production and comprehension. Journal of Psycholinguistic Research 29(2): 169-182.

Sennema, Anke, R.-van de Vijver S. E., Carroll-Zimmer-Stahl, A. 2005. Focus accent, word length and position as cues to L1 and L2 word recognition. Interdisciplinary Studies on Information Structure 03: 183-198.

Tanner, Mark-M. Landon, Melissa. 2009. The effects of computer-assisted pronunciation readings on ESL learners' use of pausing, stress, intonation, and overall comprehensibility. Language Learning and Technology 13(3): 51-65.

Trouvain, Jurgen-Gut, Ulrike (eds). 2007. Non-native prosody: phonetic description and teaching practice. Berlin/New York: Mouton de Gruyter.

Vaissière, Jacqueline. 2008. Perception of intonation. The handbook of speech perception, 236-263. doi:10.1002/9780470757024.ch10.

Venditti, Jennifer J.-Hirschberg, Julia. 2003. Intonation and discourse processing. Proceedings of ICPhS, Barcelona, 107-114.

Vijver, Ruben van de-Sennema, Anke-Zimmer-Stahl, Anne. 2006. An analysis of pitch and duration in material used to test L2 processing of words. Interdisciplinary Studies on Information Structure 00: 209-221.

Ward, Gregory-J. Birner, Betty. 2001. Discourse and information structure. In: Schiffrin, Deborah, Tannen, Deborah, Hamilton, Heidi (eds), Handbook of discourse analysis, 119-137. Oxford: Basil Blackwell.

Wennerstrom, Ann. 1994. Intonational meaning in English discourse: a study of non-native speakers. Applied Linguistics 15(4): 399-420.

Ying, H. G. 1996. Multiple constraints on processing ambiguous sentences: evidence from adult L2 learners. Language Learning 46(4): 681-711.

Wildcat Corpus of Native- and Foreign-Accented English. http://groups.linguistics.northwestern.edu/speech_comm_group/wildcat/. 